
\title{
(s)
}

\section{Are Diamond Surface Coatings Immune to Dry Running?}

\author{
Michael D. Seymour* \\ Consultant, Engineering \& Quality Systems, I Boswell Close, Kinoulton, NOTTS NG12 3ET, UK
}

\begin{abstract}
It is well understood that mechanical seal performance is dependent upon the tribology of the seal face materials. Published material is available claiming the advantages of Polycrystalline Diamond (PCD) and its suitability for extended running under dry conditions; indeed, one such claim suggests that PCD coated faces are immune to dry running. In order to investigate this claim, the author undertook a series of rigorously controlled tests to evaluate the performance of mechanical seal faces coated with a Polycrystalline Diamond coating (PCD) against others with Diamond - Like Carbon (DLC) coatings. Seal surface topography was accurately measured before and after testing and was used to evaluate the wear behaviour. From the test results obtained it is concluded that neither coatings are suitable for extended dry running use. However, it was evident that seal faces coated with a new form of DLC identified as, Plasma Assisted - Chemical Vapour Deposition (PA-CVD) performed 18 times longer than the PCD coated ones before reaching a predetermined friction induced temperature. Publications can be cited as evidence that PCD coated seal faces are capable of producing very high frictional temperatures that could, in a dry running situation, allow certain liquid fuels such as flashing hydrocarbons to reach their auto-ignition temperatures. In addition, it was revealed that the PCD coated seal units are being sold at a higher cost than the equivalent DLC coated ones by a factor of three.
\end{abstract}

Received on 10-05-2016 Accepted on 17-05-2016 Published on 24-05-2016

Keywords: Mechanical seals, Diamond-Like Carbon Coating, Polycrystalline Diamond.
'What counts is not what sounds plausible, not what we would like to believe, not what one or two witnesses claim, but only what is supported by hard evidence rigorously and sceptically examined. - Extraordinary claims require Extraordinary evidence' - Carl Sagan

\section{INTRODUCTION}

A mechanical seal assembly is a sealing device which creates a running seal between rotating \& stationary parts. Mechanical seals are mainly used as a sealing mechanism between the drive shaft and a fluid pressurised casing of a wide range of fluid machinery, including, of course, turbomachinery. Their two main functions are to provide a means of minimising any fluid leakage from the drive assembly during operational and non-operational periods. Today they replace what was generally known as 'packing' which utilised a wide range of soft materials held around a moving shaft by a 'stuffing box' to facilitate an albeit crude, but mainly effective circumferential seal.

The mechanical seal works by utilising an annular ring that rotates with the shaft and a second stationary ring fixed to the

"Consultant, Engineering \& Quality Systems, I Boswell Close, Kinoulton, NOTTS NG12 3ET, UK; Tel: 44+ (0)194981981; E-mail: seymourmd@aol.com pressurised casing. The assembly or 'cartridge' contains polymer O-rings which form a series of secondary seals that have to be carefully specified to resist chemical attack. Orings have to withstand chemical attack from the fluid being handled while, simultaneously limiting any deterioration due to high frictional or process fluid temperatures. A spring or magnetic action is used to apply a constant axial force to ensure that the sealing faces are in contact. Figure 1 depicts a typical mechanical seal assembly showing the location of the seal faces, the axial springs and polymer O-rings.

One of the essential requirements for the primary seal surfaces is that the contact faces must be flat and polished. This is normally achieved by a special machining process known as lapping. On completion, the respective primary seal surfaces are measured for flatness by viewing the surface through an optical flat whilst under a monochromatic sodium light source. Typically, Silicon Carbide $(\mathrm{SiC})$ or tungsten carbide (WC) is used as the seal face material and further developments aimed at improving resistance to wear have been to introduce a hard, low friction Diamond-Like Carbon (DLC) coating onto the contacting surfaces. The most common method of providing this coating is by ion beam disposition [1] (Appleton et al.; 1987) although other methods include: Vacuum Arc Discharge, [2] (Sablev, et al. 1974) Sputtering [3] (Deshpansey, Bunshah 1987), Pulsed Laser [4] (Chrisey and Hubler 1994), Chemical Vapour Deposition [5] 


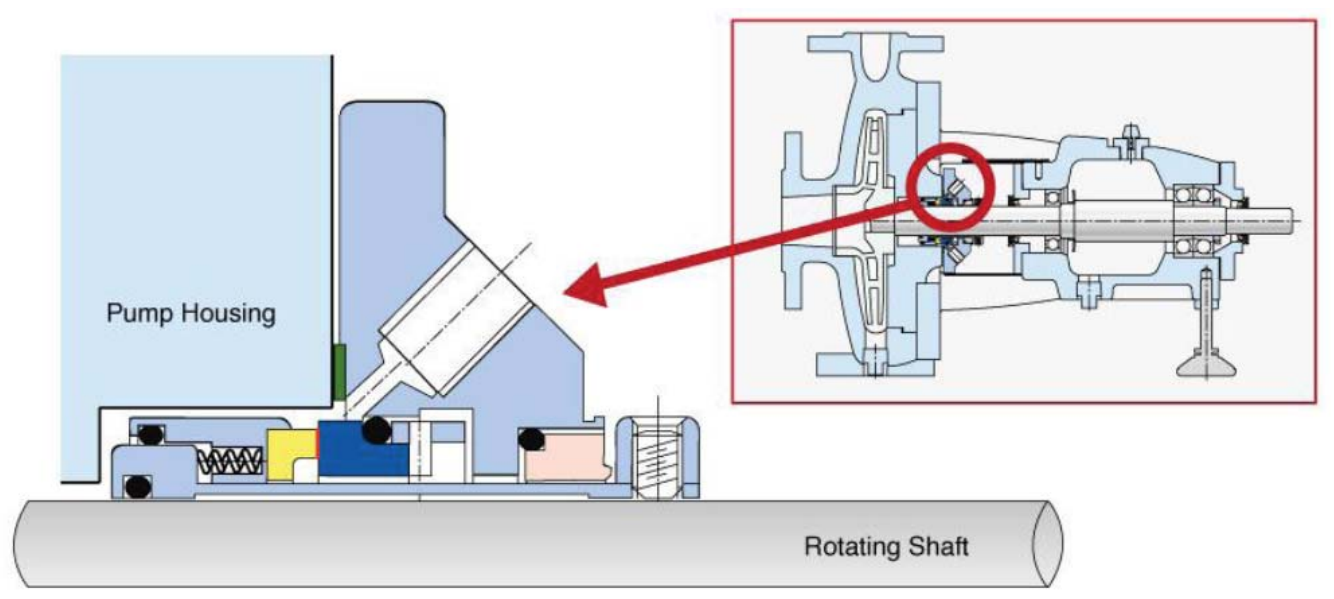

Figure 1: Mechanical seal assembly.

(Dobkin and Zuraw 2003) and more recently, Plasma Assisted - Chemical Vapour Deposition (PA-CVD) [6] described by Walker, $\mathrm{CH}$ (2015).

The aim of our test programme was to compare and quantify how effective one face surface treatment solution was relative to another. The seals had been designed and produced by two different manufacturers and involved testing by the author and his team using apparatus and measurement facilities at the Materials \& Engineering Research Institute (MERI) based at Sheffield Hallam University.

Before our tests started, it was observed that there were geometric and faces pressure differences but each seal assembly was seen as a viable solution to a number of difficult sealing applications. In addition, we noted a large cost difference between the two manufacturers' designs, one being approximately three times the cost of the other.

\section{DIAMOND LIKE CARBON (DLC) COATING}

This is a class of amorphous carbon material that displays some of the typical properties of diamond, i.e., hardness, wear resistance and low coefficient of friction. Naturally occurring diamond is almost always found in the crystalline form with a purely cubic orientation of $\mathrm{sp}$ bonded carbon atoms. The terms $\mathrm{sp}, \mathrm{sp}^{\wedge} 2$ and $\mathrm{sp}^{\wedge} 3$ are used to describe electron orbits for different types of hybridisation which are adopted for explaining the chemistry of carbon (see Figure 2). Hybridisation describes the bonding atoms from an atom's point of view.

In those hybridisation cases cubic and hexagonal lattices can be randomly intermixed, layer by atomic layer, because there is no time available for one of the crystalline geometries to grow at the expense of the other before the atoms are "frozen" in place in the material. Recent work undertaken by Frenking, et al. [7], provides further theoretical analysis of the chemical process involved in hybridisation of carbon.

Amorphous DLC coatings can result in materials that have no long-range crystalline order. As implied by the name, Diamond-Like Carbon, the value of such coatings accrues from their abilities to provide some of the properties of diamond to surfaces of almost any material. The primary desirable qualities are hardness, wear resistance, chemical resistance and low coefficient of friction. Over recent years

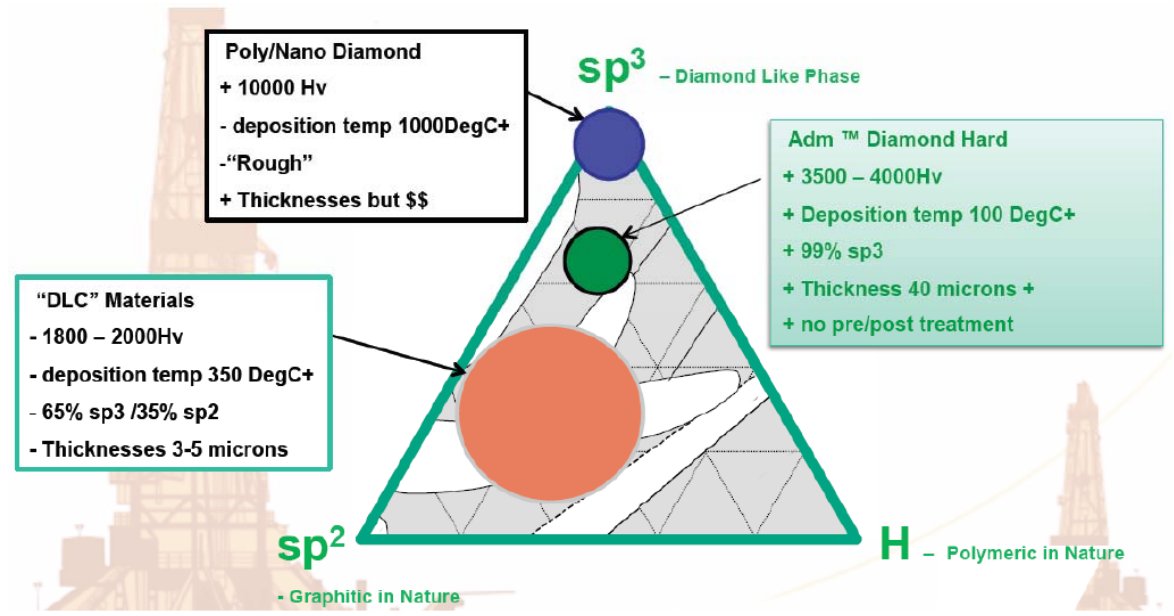

Figure 2: Material Characteristics phase diagram. 
and to date at least ten different DLC coatings have been developed; they can be defined as either Non-Plasma or Plasma processes. Under operational conditions some NonPlasma process coatings can de-layer due to poor adhesion to the substrate material and this was seen in our tests on ion beam deposition.

Plasma Assisted - Chemical Vapour Deposition (PA-CVD) is another process used to form an amorphous diamond like carbon coating. The advantage of this process is that it can be applied to a variety of substrate materials at low temperature $\left(120^{\circ} \mathrm{C}\right)$ which results in significantly extending the dry running lifetime of contacting surfaces. Although it is not recommend for extended dry running conditions, it is an ideal coating for short term intermittent operation that could occur during process disruption. In addition, this process can provide much thicker coatings in the order of 30-40 microns.

\section{POLYCRYSTALLINE DIAMOND COATING (PCD)}

Diamond can be one single, continuous crystal or it can be made up of many smaller crystals (poly-crystal). Large, clear and transparent single-crystal diamonds are typically used in gemstones. PCD refers specifically to diamond particles which have been sintered together into a coherent structure using a chemo-mechanical binder and high-pressure, hightemperature conditions. These conditions are similar to those used in single crystal diamond synthesis. The structure and conditions are unsuitable for gems and are used for industrial applications such as cutting tools and rotary seal surfaces. Polycrystalline diamond is often described by the average size (or grain size) of the crystals that make it up. Grain sizes range from nanometres to hundreds of microns, usually referred to as "nano-crystalline" and "microcrystalline" diamond, respectively. These coatings have the extreme hardness of diamonds, in the order of $10,000 \mathrm{Hv}$ and are usually produced by various means of Chemical Vapour Deposition at or above $800^{\circ} \mathrm{C}$. The various production techniques that have been developed over recent years differ by the grain size that is produced. There are several names given to these coatings such as 'ultra-crystalline diamonds', 'nano-crystalline diamonds' and polycrystalline diamonds but essentially, they are all similar. Normally, PCD coatings are 2-3 microns thick; however, these coatings can be increased - but at a price. For example, the PCD samples we tested had coating thicknesses of $10 \mu \mathrm{m}$ and were purchased 'offthe-shelf' at a much higher price than the PA-CVD coated face seals. In contrast, the PA-CVD coating method can produce greater thickness coatings of up to 40 microns and the cost is considerably lower.

\section{OTHER LOW FRICTION COATINGS}

\subsection{Tetrahedral Amorphous Carbon (ta-C)}

This Diamond-Like Carbon (DLC) is the name attributed to a variety of amorphous carbon materials containing a large proportion of $\mathrm{sp}^{3}$ bonds. Depending on the deposition method the $\mathrm{sp}^{3}$ fraction can vary from $40 \%$ to $90 \%$ and determines variations in density \& mechanical properties (see Figure 3 ). Applications as wear resistant coating are promising; the theoretically predicted high values of elastic constants are comparable to, but less than, those of diamond. Nevertheless, the predicted values with low friction coefficients have together been achieved experimentally by Xingrui Deng, et al. [8].

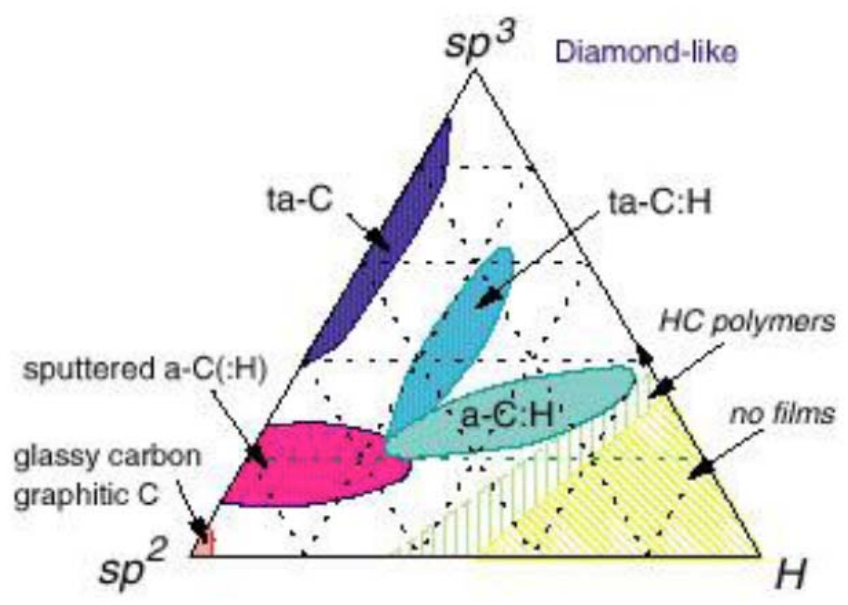

Figure 3: Materials and associated bond proportions.

\subsection{Graphene}

Graphene is fundamentally a layer of $\mathrm{sp}^{\wedge} 2$ bonded carbon atoms arranged in a honeycomb (hexagonal) lattice. It offers some very impressive properties that far exceed those of graphite as it is isolated from its 'mother material'. Graphite is naturally a very brittle compound and cannot be used as a structural material on its own due to its sheer planes (although it is often used to reinforce steel). Graphene, on the other hand, has been shown by Yilun, et al. [9] that it is the strongest material ever discovered, being more than three hundred times stronger than A36 structural steel, at 130 gigapascals, and more than forty times stronger than diamond.

In recent years, reducing friction and wear-related mechanical failures in moving mechanical systems have gained increased attention due to friction's adverse impact on efficiency, durability and environmental compatibility. Accordingly, the search continues for novel materials, coatings, and lubricants (both liquid and solid) that can potentially reduce friction and wear. Despite intense $R \& D$ efforts on graphene for a myriad of existing and future applications, its tribological potential as a lubricant remains relatively unexplored. Recently however, tribological studies based on graphene from the nano-scale to macro-scale have been reported; in particular, its use as a self-lubricating solid or as an additive for lubricating oils has been rigorously pursued as indicated by Berman, et al. (2014) [10] and evidenced by the number of papers published on the subject. 


\subsection{Superlubricity}

This is described as a state in which two contacting surfaces exhibit almost no resistance to sliding and the friction force between them nearly vanishes. Work by Meyer \& Gnecco (2014) [11] on superlubricity at the nanometre level has shown that the atomic stick-slip to slipping has been observed. If two extended contacts are moved in different directions, so called structural lubricity is seen when the two surfaces are non-matching. In addition, research work carried out by Jensen et al. (2011) [12] has shown that thermal vibrations (Thermolubricity) also leads to a reduction in friction at the nanoscale. It is evident from literature published over recent years that much research work is being undertaken worldwide into surface coatings designed to reduce friction. This is understandable as energy and material losses due to friction and wear in mechanical systems account for huge economic and environmental burdens on society. It is estimated that up to one third of the world's primary energy consumption is attributed to overcoming friction. In addition, about $80 \%$ of equipment failures are caused by wear in frictional processes. Even relatively small improvements in the tribology of mechanical systems would reap enormous societal benefits (Erdemir and Jianbin 2014) [13].

Whilst these advances in surface engineering are very interesting and exciting, potential users must consider that unless the technology can be successfully transferred from laboratory to real life operating conditions, at an acceptable cost, many will not go further than, 'an interesting concept'. It is essential that researchers understand that to enable these coatings to become commercially viable the cost of producing them must conform to the old adage, 'Best Available Technology at Net Economic Cost' (BATNEC).

\section{THE TEST EQUIPMENT \& TEST CONDITIONS}

For the dry running test programme a rigorous procedure was adopted to ensure that our results were accurate, reproducible and followed, as near as possible, field operating conditions. All our measuring equipment including, thermocouples, humidity sensors and tachometer were certified as calibrated and traceable to national standards. As many mechanical seals contain one or more polymer O-rings we decided to keep the friction induced seal face temperature below $250^{\circ} \mathrm{C}$ to ensure that we did not influence the performance of the ' $\mathrm{O}$ ' seals by exceeding the manufacturers recommended maximum operating temperature. It is well known that certain polymer O-ring materials can operate up to $327^{\circ} \mathrm{C}$ using perfluoro elastomers but, in most cases, the O-ring material will be rated at temperatures below this temperature. As these O-rings perform such an important function, the author and his team decided to limit the face temperature to $250^{\circ} \mathrm{C}$ and when this was reached the test run was stopped and the time from start to finish recorded.

The test equipment comprised a three phase, $5.5 \mathrm{KW}$ electric motor revolving a $47.6 \mathrm{~mm}$ (1.875 ins) diameter test shaft at different speeds of $2827-2521 \mathrm{rpm}$ respectively to accommodate slightly different diameter seal faces calculated to produce a consistent seal face velocity of $8.0 \mathrm{~m} / \mathrm{sec}$. Temperature measurements were made using calibrated type $\mathrm{K}$ thermocouples that were located as shown below and mounted $180^{\circ}$ apart on the internal diameter of the stationary face with high temperature adhesive tape.

Two further temperature sensors were placed close to the rotary seal surfaces through the flush \& drain ports and another located to measure the ambient test cell temperature. In addition a calibrated humidity sensor was located near to the seal assembly under test to measure changes in humidity. All measurements of temperature, seal face velocity, relative humidity and test run times were recorded on a data logger.

Work by Chowdhury, et al. (2012) [14] and Lancaster JK, (1990) [15] has shown that face velocity and relative humidity are the two factors that can influence the coefficient of friction and hence its effect on wear on dry running surfaces. In practice, of course, the fluid being pumped acts as a lubricant and it is only when a process malfunction occurs will the seal faces eventually run dry.

\section{PRE \& POST-TESTING MEASUREMENTS}

Two test assemblies with $\mathrm{SiC}$ faces of each coating type (PA$C V D$ ) identified as $C 1 \& C 2$ and type (PCD), identified as $D 1$

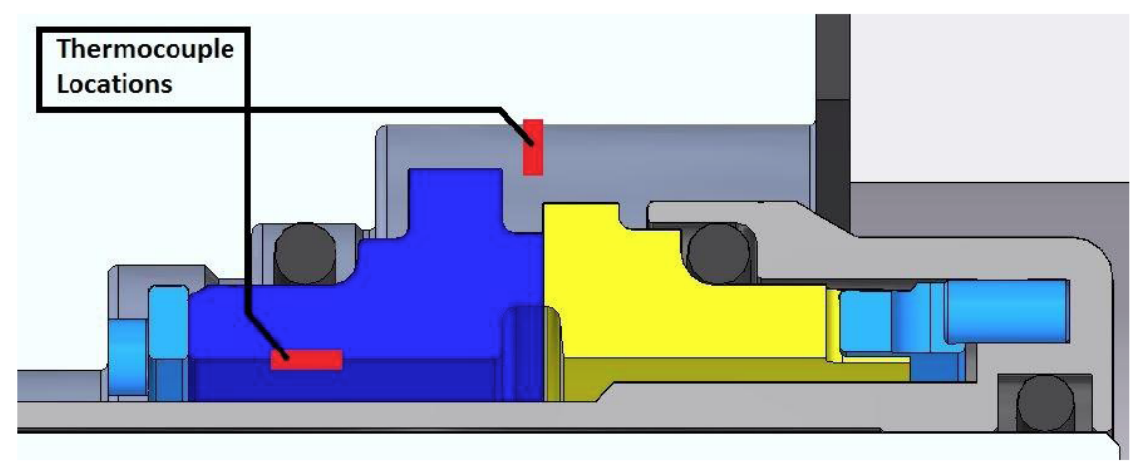

Figure 4: Thermocouple locations. 
\& D2 were fixed to the test rig and run consecutively until the frictional induced temperature, set at $250^{\circ} \mathrm{C}$, was reached and the test terminated. Before the tests started, measurements and calculations were made to establish the face contact pressures for each assembly and they were:

\section{Table 1: Seal Face Contact Pressures}

\begin{tabular}{|c|c|c|}
\hline $\mathrm{C} 1 \& \mathrm{C} 2$ & $234.4 \mathrm{kPa}$ & $\left(34 \mathrm{lbf} / \mathrm{in}^{2}\right)$ \\
\hline $\mathrm{D} 1 \& \mathrm{D} 2$ & $110 \mathrm{kPa}$ & $\left(16 \mathrm{lbf} / \mathrm{in}^{2}\right)$ \\
\hline
\end{tabular}

To enable us to reach meaningful conclusions supported by strong evidence, we needed to measure the coated seal face topography of each sample before and after testing. Measurements were made independently by the Materials \& Engineering Research Institute (MERI) based at Sheffield Hallam University. For form \& roughness measurement, MERI used an Alicona Infinite Focus Microscope, to measure the topography across the diameter of each annular face in the locations and direction, as indicated in Figure 5 below. This instrument is a non-contacting optical 3D microcoordinate system capable of measuring surface profiles with a vertical resolution and lateral resolution down to $10 \mathrm{~nm}$ and $400 \mathrm{~nm}$ respectively.

The coating thickness for $\mathrm{C} 1$ \& $\mathrm{C} 2$ was measured by the suppliers at $10 \mu \mathrm{m}$ and the coating thickness for samples D1 \& D2 was also $10 \mu \mathrm{m}$ thick.

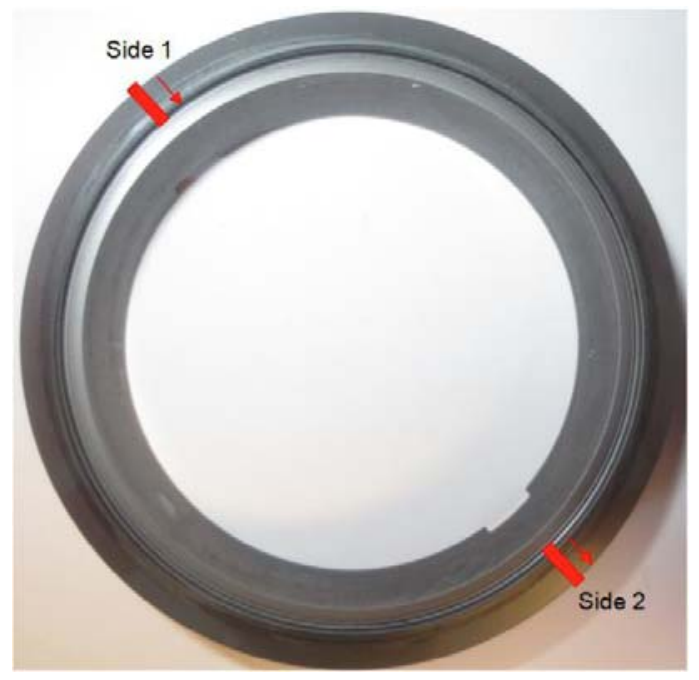

Figure 5: Scan profile location and direction.

Throughout the testing of each assembly the Relative Humidity was measured inside the test cell and these measurements were:

Table 2: Relative Humidity Measurements

\begin{tabular}{|c|c|}
\hline C1 & $37.84 \%$ \\
\hline C2 & $31.53 \%$ \\
\hline D1 & $39.11 \%$ \\
\hline D2 & $37.45 \%$ \\
\hline
\end{tabular}
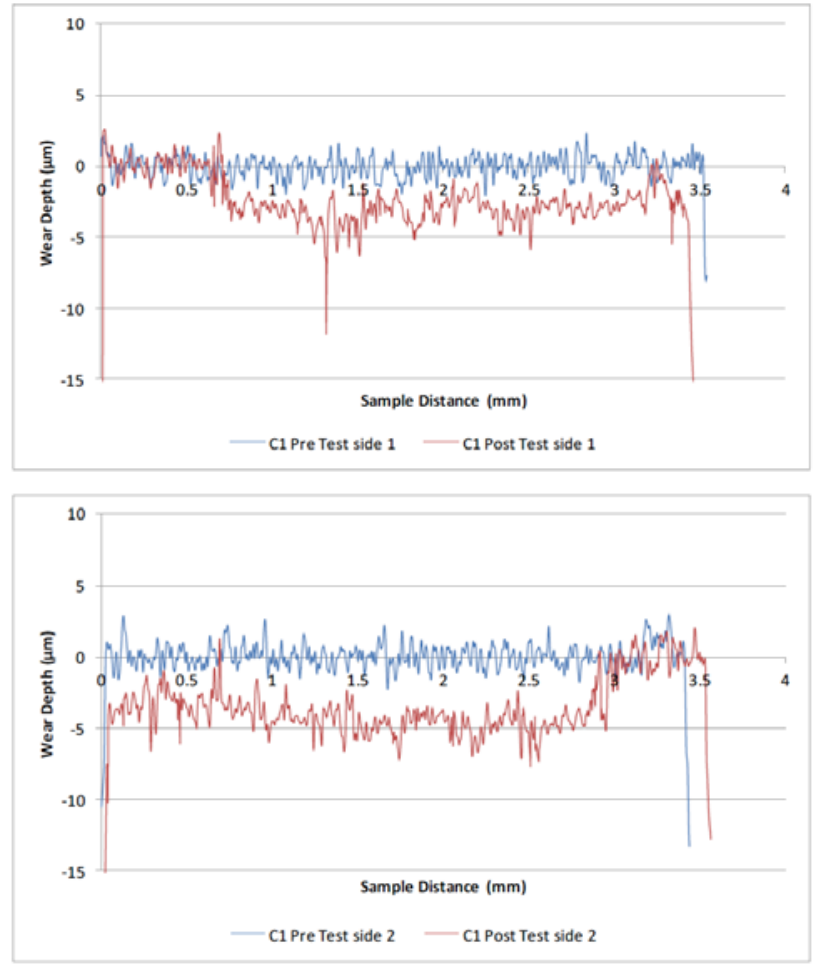

Figure 6: $\mathrm{C} 1$ - sides $1 \& 2$ face profiles before $\&$ after running dry for $1 \mathrm{~h}: 47 \mathrm{~m}: 27 \mathrm{~s}$.
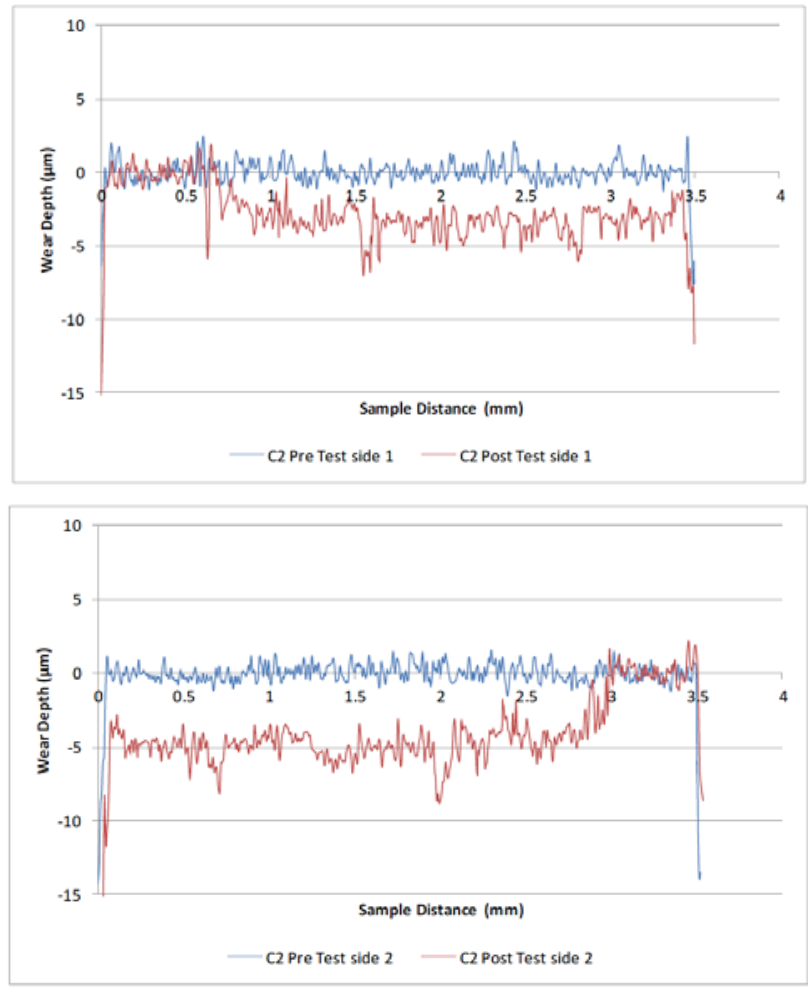

Figure 7: C2 - sides $1 \& 2$ face profiles before \& after running dry for 1h: $46 \mathrm{~m}: 04 \mathrm{~s}$.

\section{RESULTS \& DISCUSSION}

The measurements recorded in Figures 6-9 shows the surface topography before and after dry running tests and 

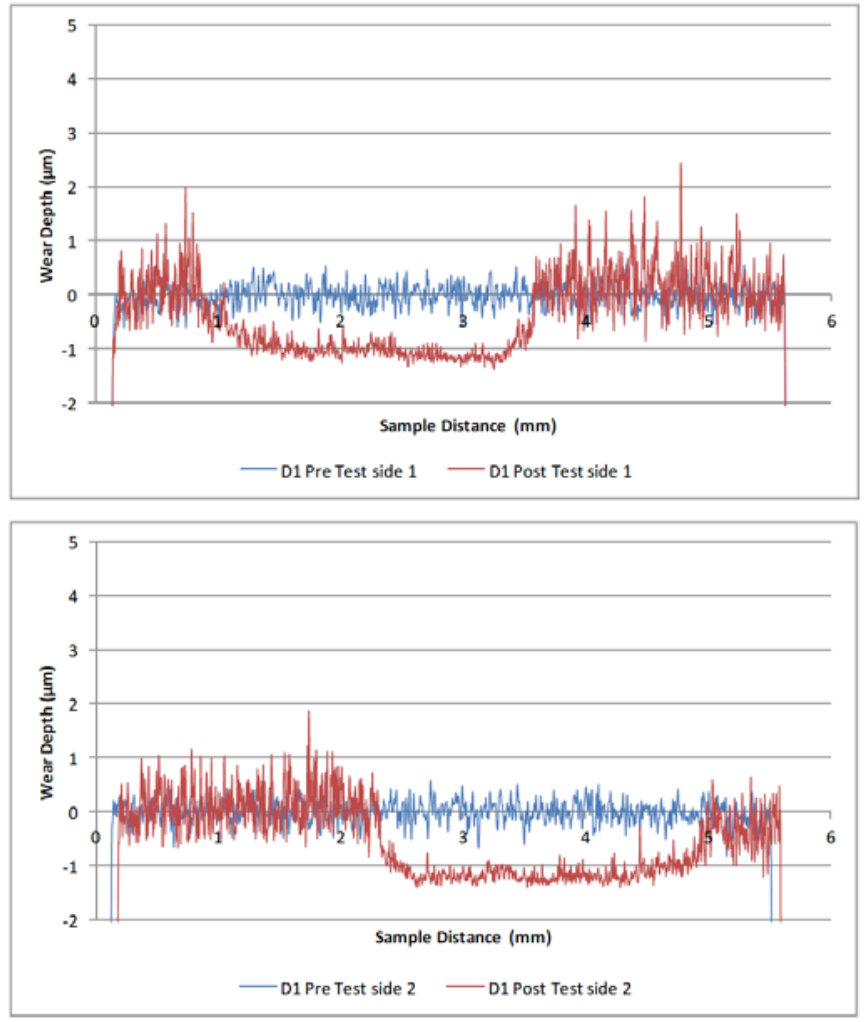

Figure 8: D1 sides $1 \& 2$ face profiles before \& after running dry for $5 \mathrm{~m}: 51 \mathrm{~s}$.
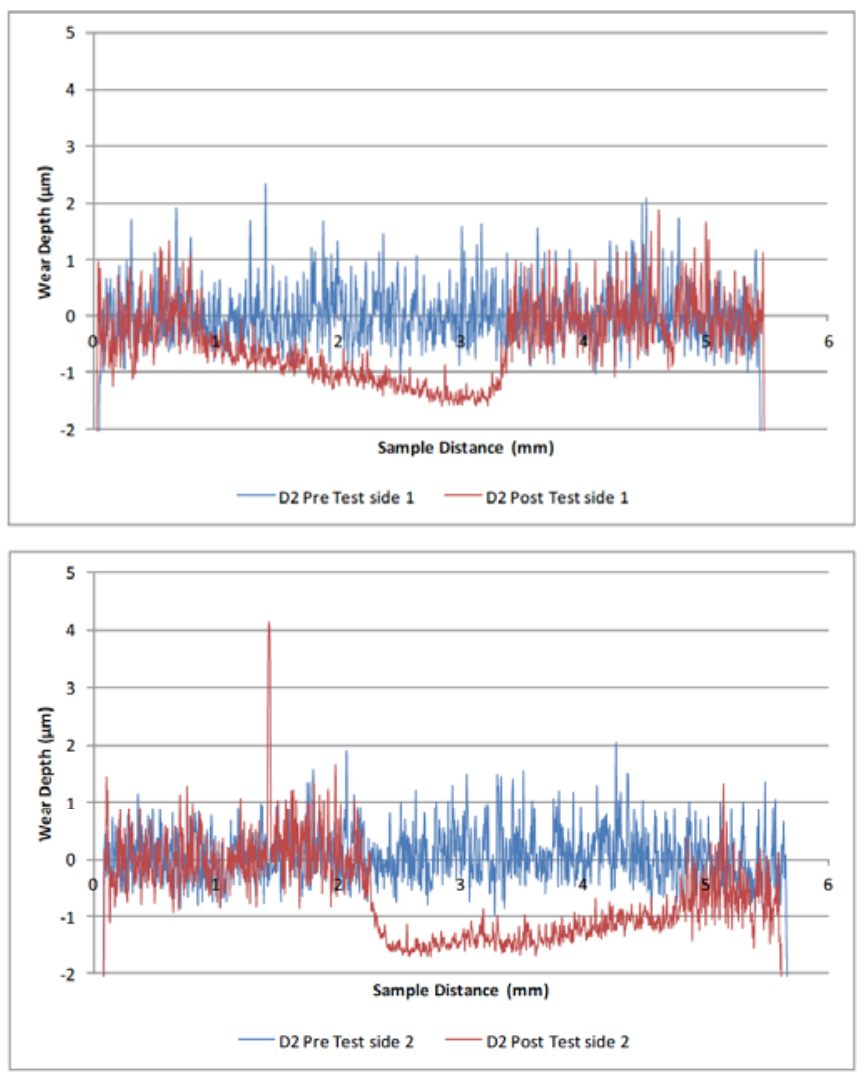

Figure 9: D2 face profile before \& after running dry for $1 \mathrm{~m}: 49 \mathrm{~s}$.

indicate the depth and location of wear across the faces at the two diametrically opposite locations. They also show, in red, the amount and depth of wear compared with the surface topography before the test, shown in blue, which were notionally the same. Following the testing of assemblies C1 \& C2 it is shown that wear has taken place over about $80 \%$ of the surface to an average depth of approximately $4 \mu \mathrm{m}$ with very little wear on the inside edges of both samples. This depth of wear was expected as these tests were run dry with only the PA-CVD coating acting as a dry lubricant. It was therefore revealing that these faces lasted as long as $1 \mathrm{~h}$ : $46 \mathrm{~m} \& 1 \mathrm{~h}: 47 \mathrm{~m}$ respectively, although this coating was never designed to be used for extended dry running. What was surprising is the consistency of these two results being within $1 \mathrm{~m}$ : $23 \mathrm{~s}$ of each other before reaching $250^{\circ} \mathrm{C}$. As the Relative Humidity, measured during the tests, varied only slightly it is doubtful that it had any major influence in reducing the face friction.

It was also observed that wear rates, measured in microns/hour, of the two surface coatings were significantly different as shown below in Table $\mathbf{3}$.

Table 3:

\begin{tabular}{|c|c|}
\hline $\begin{array}{c}\text { Dry Running 1.875" Single Seal } \\
\text { (8m/s sliding speed) }\end{array}$ & Wear $(\boldsymbol{\mu m})$ per hour \\
\hline \hline C1 & 2.25 \\
\hline C2 & 2.53 \\
\hline D1 & 10 \\
\hline D2 & 50 \\
\hline
\end{tabular}

An in depth investigation into why the wear rates are so different would be the subject of further research into the structure, grain size and application methods of both coatings. This was not the aim of our test programme which was to, 'compare the effectiveness of one face surface treatment solution to another'. Interestingly, the international company who produce the seal assemblies, identified as D1 $\& D 2$, quote in their marketing literature that 'wear, in pure dry running mode, is an outstanding $0.08-0.2 \mu \mathrm{m} / \mathrm{h}$ '. Our dry running wear rate measurements and calculations have shown differences by factors of between 4 to 20 times greater in favour of the PA-CVD coating. Unless a more in depth scientific investigation is undertaken the reason(s) for the differences remains unclear and can only be demonstrated by comparative testing. In addition, suppliers of these coatings would be most reluctant to reveal details of their processes for obvious commercial confidentiality.

One of several different observations obtained under identical test conditions can be seen in Figures $\mathbf{8}$ and $\mathbf{9}$, by comparing the initial topography of D1 \& D2, in blue, D1 being similar in profile to samples C1 \& C2. However, as the profiles, C1 C2 \& D1, were comparable it was expected that the PCD coated faces would last as long or maybe even longer, than the PACVD ones; but this was not the case as the tests only lasted, $5 \mathrm{~m}: 51 \mathrm{~s} \& 1 \mathrm{~m}: 49 \mathrm{~s}$ respectively. Whereas, in sample D2 a much rougher profile was measured and as expected, it took 


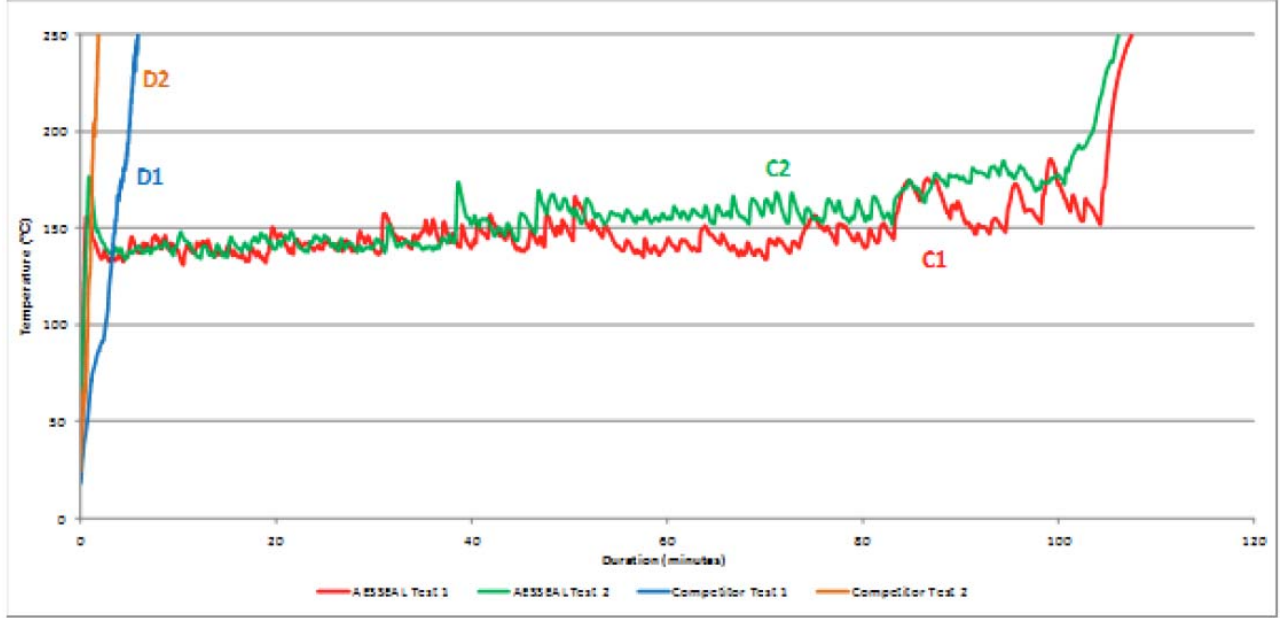

Figure 10: Test duration time in minutes to reach $250^{\circ} \mathrm{C}$.

less time to reach the friction induced cut-off temperature of $250^{\circ} \mathrm{C}$. Post test measurements show that the depth of wear on the PA-CVD coated faces is deeper by a factor of between 4 \& 5 than the PCD coated faces. This result was not surprising as the greater depth of wear was possibly caused by a combination of a longer running period $(x 18)$ and a higher face contact pressure, $(234 \mathrm{kPa}$ for $\mathrm{C} 1 \& 2$ and $110 \mathrm{kPa}$ for D1\&2).

Further promotional material in the form of a publically available 'YouTube' video [16] shows a dry running test being performed to compare an untreated $\mathrm{SiC}$ face seal assembly with one that was PCD coated. A remote temperature sensor showed that the PCD coated seal was producing friction induced temperatures of up to $360^{\circ} \mathrm{C}$ after $30 \mathrm{~min}$ but, nevertheless, was still intact. Whereas, the $\mathrm{SiC}$ seal unit only lasted 28 seconds before destruction. Whilst this is visually impressive and no doubt technically correct, what would happen to the polymer ' $O$ ' rings that are only effective at lower temperatures? Also, what if these seals were operating at this temperature when processing a fluid with a low autoignition temperature - the minimum temperature required to ignite a gas or vapour in air without an ignition source being present? For example, petrol $\left(247^{\circ} \mathrm{C}\right)$ or diesel $\left(210^{\circ} \mathrm{C}\right)$ [17] would ignite in the event of the pumping process being interrupted thus allowing the seals to run dry. In both these high friction induced temperature scenarios a potentially hazardous state could occur. That is why it is strongly recommended for users not to operate these coated seals for extended periods in a dry running condition. In addition, one company claims, in a recently published document, that, 'The Diamond Coating (PCD) makes the seal immune to dry running and solids in the medium'. The author finds this statement difficult to understand even though the article refers to a bellows type seal where polymer ' $O$ ' seals are not used but, the diagram referred to in the article clearly shows 'O' ring seals.

Figure 10 graphically represents the results confirming the aim of our test programme clearly demonstrating that seal assemblies C1 \& C2 performed significantly better in terms of extended running times than the other two assemblies, D1 \& D2.

\section{REVIEW OF RELATIVE COSTS}

The average wholesale price of a Gemological Institute of America (GIA) Certified Cut, one carat diamond, currently ranges between $\$ 3,080$ and $\$ 26,950$. The wide variations in price depend upon the four 'C's: cut, colour, clarity \& carat and these are defined in a series of tables produced by The Diamond Registry [18]. It appears that the price of some Synthetic Diamond Coatings are equal to or greater than, the price of a low quality one carat diamond solitaire. Users should be aware that they are paying a high price but may be getting very limited dry running capability in, for example, a process pump in return for their investment.

\section{CONCLUSIONS}

(1) It was evidently clear from the test work we have carried out that Diamond-Like Carbon (DLC) coating on the SiC faces of mechanical seals are not suitable for extended periods of dry running.

(2) Polycrystalline Diamond coating (PCD) seal faces were found to be completely unsuited for extended dry running use as they performed, in terms of dry running time, poorly against the equivalent PA-CVD coated faces by a factor of eighteen, as shown in Figure $\mathbf{1 0}$ above. We have demonstrated that in the unlikely event of a process being interrupted the PA-CVD coated seals would perform longer and safer, in the short term under dry running conditions than the PCD coated equivalent.

(3) Users should beware that dry running these seals for extended periods will create high temperatures that will damage the O-rings sufficiently for them to become ineffective. In addition, high frictional 
temperatures could, when processing certain products, exceed their auto-ignition temperature and cause a fire.

(4) A high wear rate was measured on the PCD coated faces providing evidence that under extreme dry running conditions the PA-CVD coating performed significant better by factors of between 4-20 times.

(5) Although a precise difference in seal unit costs is difficult to obtain, it is generally recognised that PCD faced coatings can be up to three times the cost of the equivalent PA-CVD coating process.

(6) Finally, users and buyers should be aware that, 'Diamond coatings are not immune to dry running', as our rigorous test programme has revealed. The testing of two different manufacturers' equivalent mechanical seal assemblies showed that both design solutions were effective for short periods of time. However, the PA-CVD coating lasted considerably longer than the more costly PCD coated seal faces.

\section{ACKNOWLEDGEMENTS}

The author gratefully acknowledges the assistance he has had from the Materials \& Engineering Research Institute (MERI) based at Sheffield Hallam University.

\section{REFERENCES}

[1] Appleton BR, Zuhr RA, Noggle TS, Herbots N, Pennycook SJ, Alton GD. Ion Beam Deposition. MRS Bulletin 1987; 12: 52-59.

[2] Sablev LP, et al. Apparatus for Vacuum-Evaporation of Metals Under the Action of an Electric Arc, US Patent \#3,783,231, 01 Jan. 1974.
[3] Deshpansey CV, Bunshah RF. Diamond \& Diamond- Like Films: Deposition, Processes \& Properties: J Vac Sci Technology, A7(3) 2294 (1987). Also, Altshuler,A. Diamond Technology in the USSR: From Synthesis to Application, Delphic Associates (1990)

[4] Chrisey DB, Hubler GK. Pulsed Laser Deposition of Thin Films John Wiley \& Sons, 1994; ISBN 0-471-59218-8.

[5] Dobkin and Zuraw. Principles of Chemical Vapour Deposition. Kluwer 2003; ISBN 1-4020-1248-9.

[6] Walker $\mathrm{CH}$. 14th EDF/Pprime Workshop: Futurescope Oct 8th 2015, Innovative geometrical enhancement and use of composite coating structures to improve lifetime \& performance of thrust bearings.

[7] Frenking G, Shaik S, Eds. "Chapter 3: The NBO View of Chemical Bonding". The Chemical Bond: Fundamental Aspects of Chemical Bonding. John Wiley \& Sons 2014. ISBN 9783527664719 http://dx.doi.org/10.1002/9783527664696

[8] Xingrui $\mathrm{D}$, et al. Tribological Behaviour of tetrahedral Amorphous Carbon (ta-C) Coatings at Elevated Temperatures. Tribology International 2014; 75; 93-103. http://dx.doi.org/10.1016/j.triboint.2014.04.002

[9] Liu Y, Xie B, Zhang Z, Zheng Q, Xu Z. Mechanical properties of graphene papers. Journal of the Mechanics and Physics of Solids 2012; 60(4): 591-605. http://dx.doi.org/10.1016/j.jmps.2012.01.002

[10] Berman D, Erdemir A, Surmant AV. Graphene: a new emerging lubricant. Materials Today 2014; 17(1): 1-42.

[11] Meyer, Ernst \& Gnecco, Enrico, Superlubricity on nanometre scale. Friction 2014; 2(2): 106-113. ISSN 2223-7690

[12] Jansen L, Holscher H, Schirmeisen A. Temperature dependence of atomic scale stick-slip friction. Phys Rev Lett 2011; 104: 256101. http://dx.doi.org/10.1103/PhysRevLett.104.256101

[13] Erdemir, Ali, Jianbin, Luo, Guest Editorial: Special Issue on Superlubricity. Friction 2014; 2(2): 93-94. ISSN 2223-7690

[14] Chowdhury MA, Nuruzzaman DM. AbdulHannan MD,/ International Journal of Engineering Research and Applications (IJERA)ISSN: 2248-9622 www.ijera.com Vol. 2, Issue 2,Mar-Apr 2012, pp.14251431

[15] Lancaster JK. The influence of environmental humidity on friction, lubrication \& wear. Journal of Tribology 1990; 23.

[16] https://www.youtube.com/watch?v=mndO_uC3bXA

[17] Zabetakis MG. Flammability characteristics of combustible gases and vapours, U.S. Department of Mines, Bulletin 1965; 627

[18] The Diamond Registry. Available from: http://www.diamondregistry. $\mathrm{com} /$

(c) 2016 Michael D. Seymour; Licensee Lifescience Global.

This is an open access article licensed under the terms of the Creative Commons Attribution Non-Commercial License (http://creativecommons.org/licenses/by-nc/3.0/) which permits unrestricted, non-commercial use, distribution and reproduction in any medium, provided the work is properly cited. 